\title{
Revista Brasileira de Enfermagem REBEn \\ Concepções de saúde e itinerário terapêutico adotado por adultos de um município de pequeno porte
}

\author{
Conceptions of health and therapeutic itinerary adopted by adults from a small city \\ Concepciones de salud y rutina terapéutica adoptada por adultos de una ciudad de \\ pequeño porte
}

\section{Maria de Fátima Garcia Lopes Merino}

Enfermeira. Mestre em Enfermagem pela Universidade Estadual de Maringá, PR.

Sônia Silva Marcon

Enfermeira. Doutora em Enfermagem. Professora da Graduação e Pós-graduação em Enfermagem na Universidade Estadual de Maringá, PR.
Submissão: $19 / 06 / 2007$

Aprovação: 21/10/2007

\section{RESUMO}

Estudo descritivo desenvolvido com o objetivo de identificar as concepções de saúde e o itinerário terapêutico adotado por indivíduos adultos em um município de pequeno porte. Os dados foram coletados no mês de julho de 2006 por meio de entrevista semi-estrutrada junto a 29 indivíduos. Constatou-se que os homens referem menos problemas patológicos do que as mulheres e que estas, em sua maioria, iniciam a busca pela solução de problemas de saúde mais precocemente e no sistema formal de saúde. Conclui-se que existem diferenças entre os sexos na maneira de reconhecer a doença e buscar soluções e isto precisa ser considerado pelo sistema de saúde, de forma a facilitar o acesso dos indivíduos respeitando suas particularidades e individualidades. Descritores: Conduta de saúde; Condições de saúde; Comportamento de procura de cuidados de saúde; Atitude frente a saúde.

\section{ABSTRACT}

Descriptive study, developed with the objective of identifying the conceptions of health and the therapeutic itinerary adopted by adult individuals in a small city. Data was collected during the month of July 2006 using semi-structured interviews with 29 individuals. It was observed that men make fewer references to pathological problems than women, who mostly seek solution for health problems sooner, using the public healthcare system. It was concluded that there are differences between the genders when it comes to recognizing illness and seeking solutions, and that this must be taken into account by the healthcare system, in order to facilitate patient access while respecting the uniqueness and individuality.

Descriptors: Health behavior; Health Status; Patient acceptance of Health care; Attitude to Health.

\section{RESUMEN}

Estudio descriptivo desarrollado con el objetivo de identificar las concepciones de salud y la rutina terapéutica adoptada por individuos adultos en un municipio de pequeño porte. Los datos se recogieron en el mes de julio de 2006, a través de entrevista semi estructurada entre 29 individuos. Se constató que los hombres refieren menos problemas patológicos que las mujeres y éstas, en su mayoría, se dedican a la búsqueda de soluciones a problemas de salud ates que los hombres y lo hacen en el Sistema Formal de Salud. Se concluyó que hay diferencias entre los sexos en la forma de reconocer la enfermedad y de buscar soluciones y esto necesita ser tomado en cuenta por el sistema de salud, a fin de facilitar el acceso de los individuos, respetando sus particularidades e individualidades.

Descriptores: Conducta de salud; Estado de salud; Aceptación de la atención de salud; Actitude frente a la salud.

Merino MFGL, Marcon SS. Concepções de saúde e itinerário terapêutico adotado por adultos de um município de pequeno porte. Rev Bras Enferm 2007 nov-dez; 60(6): 651-8.

\section{INTRODUÇÃO}

As concepções de saúde entre os indivíduos são determinadas de acordo com o meio em que estão inseridos, sendo influenciadas pela sociedade, comunidade, família, além do conhecimento da ciência e tecnologia, as quais cada indivíduo tem acesso. A concepção científica sobre a saúde, de uma maneira geral, é aceita pelos indivíduos como verdadeira, pois para eles as crenças e valores médicos também apresentam respostas socialmente organizadas para a doença ${ }^{(1)}$.

São as experiências individuais e as influências sociais que desencadeiam as diferenças existentes nas diversas sociedades entre homens e mulheres, e podem influenciar suas concepções sobre a saúde, e suas atitudes na busca pela atenção à saúde.

A análise do processo saúde-doença, na perspectiva de gênero, nos permite introduzir novos elementos à noção de causalidade das doenças, a partir da aceitação de diferenças dos processos de adoecimento e 
morte como resultado das relações de gênero.

As diferenças no estado de saúde entre os sexos se relacionam com fatores biológicos, mas não se limitam somente a questões reprodutivas, genéticas, hormonais e metabólicas que, embora desempenhem um papel importante nas diferenças dos padrões patológicos, não são as únicas ${ }^{(2)}$. 0 gênero é um conceito que incorpora os fatores sociais associados aos diferentes padrões de socialização de homens e mulheres, que tem a ver com a organização familiar, as condições de trabalho, o tipo de ocupação e a cultura, os quais por sua vez, interferem no processo saúde-doença(2).

Os sujeitos, homem e mulher, se apresentam em um processo "continuado e dinâmico", portanto não acabado quando no momento do nascimento, mas que se constrói através das "práticas masculinizantes e feminizantes" de acordo com cada sociedade, estando, portanto, inserido nas instituições sociais (igreja, escola, etc), que expressam as relações sociais de gênero(3).

Na cultura ocidental, desde a infância, as pessoas são direcionadas, tanto pela família quanto pelos grupos sociais aos quais pertencem, a desempenharem determinados papéis de gênero. Homens e mulheres são condicionados a assumirem padrões comportamentais do cotidiano como algo natural para o sexo masculino e feminino.

O masculino e o feminino, da forma como são aceitos em nossa sociedade, definem um perfil esteriotipado de homem e de mulher. Os homens são vistos como ativos, fortes, capazes do trabalho físico árduo, produtivos, competitivos e orientados, enquanto as mulheres como sensíveis, frágeis, dependentes e geralmente mais aptas ao cuidado. Neste contexto, cabe aos homens a responsabilidade por demonstrar força e a capacidade de estarem sempre em boas condições de saúde, a fim de manter o trabalho e o sustento da família, e às mulheres cabe o papel de "cuidadora" da própria saúde e também da saúde dos demais membros da família( ${ }^{(4)}$. As atribuições simbólicas diferenciadas entre homens e mulheres, resultam muitas vezes em situações que predispõem os homens a assumirem certos comportamentos que põem em risco sua saúde e/ou desencadeiam processos patológicos ${ }^{(4)}$. Estas construções de gênero definem a maneira como os homens usam e percebem o seu corpo, podendo muitas vezes, graças a seus modelos de masculinidade, assumirem comportamentos menos saudáveis em relação às mulheres ${ }^{(5)}$. Em escritos do século 17 já se comentava ser menor a freqüência de doenças nos homens, embora fosse maior sua mortalidade, e também o fato de que as mulheres eram duas vezes mais consultadas pelos médicos ${ }^{(6)}$. No que diz respeito ao sexo feminino, estudos demonstram que as mulheres apresentam queixas mais freqüentemente do que os homens $\mathbf{s}^{(6,7)}$, avaliam pior o seu estado de saúde, consultam mais os médicos e declaram mais suas doenças, além de se submeterem a mais exames ${ }^{(8)}$.

Embora sejam escassos os estudos abordando a procura de serviços formais de saúde por parte dos homens, existem suposições de que os indivíduos do sexo masculino preferem utilizar mais outros tipos de serviços de saúde como farmácias por estes estabelecimentos responderem de forma mais objetiva às suas necessidades, sendo possível nestes locais receber atendimento mais rápido e expor seus problemas com maior facilidade, além do fato de que os homens consideram as instituições formais de saúde como as UBSs (Unidades Básicas de Saúde), um espaço feminilizado freqüentado em sua maioria por mulheres, idosos e crianças e ainda, que estes locais não disponibilizam programas específicos à esta população( ${ }^{(5)}$.

De fato, as mulheres mantém com as instituições formais de saúde uma maior aproximação que se destaca pela sua utilização no período gravídicopuerperal, além de serem elas, na maior parte das vezes, responsáveis pelo cuidado em seus domicílios das crianças e idosos, e que são os extremos da cadeia etária e os que mais se utilizam dos serviços de saúde.

Embora, pelos fatores já expostos, a mulher se torne mais predisposta à utilização destes serviços e os dados apontem para uma maior morbidade para este sexo, de uma maneira geral, a experiência da doença leva os indivíduos, tato mulheres como homens, a buscarem por alguma alternativa para o alivio de suas dores e/ou sofrimento.

O processo de escolha pelo caminho a ser seguido na busca da solução do problema existente segue um itinerário de cura ou Itinerário Terapêutico. As trajetórias de cada indivíduo neste percurso são viabilizadas em um campo de possibilidades sócio-culturais que permitem a elaboração e implementação de projetos de tratamentos.

Na busca pela solução de seus problemas de saúde, os indivíduos desenvolvem ações de apoio que envolve suas redes de relações como os familiares, vizinhos, terapeutas populares, organizações religiosas ou os próprios serviços de saúde, entre outras possibilidades, sendo a família a primeira forma de assistência informal deste processo(9). Isso ocorre porque algumas doenças são vistas como de menor intensidade ou preocupação por parte dos indivíduos. Em geral, as pessoas retratam opiniões como "doença leve pode ser tratada em casa, doença grave é que precisa de médico"(10).

Como a maioria dos estudos relativos a esta questão foram desenvolvidos em grandes centros ${ }^{(5-7,11)}$ surgiu o seguinte questionamento: Será que os moradores de pequenas localidades, formada por uma população ribeirinha, apresentaria diferença de gênero em suas concepções e comportamentos em saúde?

Para responder a estas questões definiu-se como objetivo deste estudo compreender as concepções de saúde e doença e conhecer o itinerário terapêutico adotado por adultos no município de Porto Rico-PR.

\section{METODOLOGIA}

O estudo foi realizado no município de Porto Rico, localizado na região noroeste do estado do Paraná, às margens do rio Paraná. Aárea urbana do município é pequena, conta com apenas quatro ruas paralelas. A região onde o município está localizado envolve o único trecho não represado do rio Paraná em território brasileiro, consistindo um importante ecossistema, pois as cheias e vazantes que ocorrem na região são determinantes para manter o equilíbrio ambiental dessas áreas ${ }^{(12)}$. Esta região tornou-se um laboratório natural de pesquisa onde são desenvolvidos estudos que envolvem comunidades biológicas e os aspectos ambientais, estudos das comunidades humanas e as relações destas com o ambiente, com os processos de ocupação e de degradação que este vem sofrendo, e a busca de uma melhoria nas condições de vida da população( $0^{(2)}$.

Trata-se de uma pesquisa qualitativa, que adotou como técnica de coleta de dados, entrevistas individuais com indivíduos adultos (idade entre 20 e 59 anos) de ambos os sexos. O tamanho do grupo foi definido a partir da saturação dos dados ${ }^{(15)}$. Os dados foram coletados no mês de junho de 2006, nos sete dias da semana, tendo por objetivo entrevistar também os homens em suas residências, os quais, em sua maioria, trabalham durante a semana. Para análise e interpretação do material coletado utilizou-se a técnica de análise de conteúdo (análise temática) proposta por Minayo ${ }^{(13)}$. Os informantes do estudo foram identificados pelas letras $\mathrm{H}$ para homens e $M$ para mulheres, seguido de um número que indica a ordem em que foram incluídos no estudo e a idade dos mesmos.

O desenvolvimento do estudo obedeceu aos preceitos éticos disciplinados pela Resolução n 196 do Conselho Nacional de Ética e Pesquisa (CONEP). E seu projeto foi aprovado pelo Comitê de Ética da Universidade Estadual de Maringá (Parecer $n^{0} 217 / 04$ ). Todos os participantes que aceitaram participar da pesquisa assinaram o Termo de Consentimento Livre e Esclarecido em duas vias.

\section{RESULTADOS E DISCUSSÃO}

A amostra entrevistada foi constituída por 13 homens e 16 mulheres, com uma média de idade de 42 e 38 anos respectivamente. Dentre os entrevistados constatou-se que todos os homens apresentavam atividades laborais fossem elas fixas ou não, enquanto que dentre as mulheres apenas $40 \%$ desenvolviam atividades de trabalho fora do domicílio que lhes oferecesse alguma renda. $A$ maior parte dos entrevistados de ambos os sexos eram casados e apresentavam uma renda familiar média de dois salários mínimos, com variação 
entre um e seis salários. O nível de escolaridade dos entrevistados variou entre não alfabetizado $(3,5 \%)$ e nível superior $(10,3 \%)$, com predomínio do ensino fundamental incompleto, não havendo diferenças importantes entre os sexos.

Ao se investigar as concepções de saúde dos indivíduos em estudo, observou-se que para a maioria das pessoas $(51,7 \%)$, tanto por parte dos homens quanto das mulheres, prevalece a idéia de que ser saudável está relacionado à ausência de sintomas e doenças e uma percepção de bem estar:

"Équando ela (a pessoa) estábem fisicamente, mentalmente". (M6-38anos)

"Quando não está sentindo nada". (M10-28 anos)

O conceito de saúde descrito pela maioria dos entrevistados é coerente com aquele adotado pela Organização Mundial de Saúde, que valoriza não apenas a ausência de doença, mas a situação de perfeito bem estar físico, mental e social da pessoa.

A questão da formulação da concepção de saúde pelos indivíduos é como algo relacionado com o homem e o seu ambiente e a satisfação de uma vida ativa. Enquanto a doença chama a atenção pela sua presença, a saúde não desperta o interesse das pessoas. Permanecendo escondida, revela-se através de bem-estar, e somente nos momentos de fadiga, esforço ou cansaço é que o indivíduo percebe alguma alteração em seu estado ${ }^{(14)}$.

Apesar do conceito formulado por parte dos entrevistados de "saúde como a ausência de doença", eles não deixaram de citar também a capacidade funcional, a autonomia, a independência e as relações sociais.

"Uma pessoa assim tipo normal, que ela anda, conversa, ela faz o que tem que fazer, normal".(M14-25 anos)

De suas manifestações, foi possível extrair o que eles consideram condições essenciais para o alcance de um estado satisfatório de saúde como ser feliz, ter um trabalho, ter sono e repouso adequado, estar com disposição para desenvolver atividades do dia a dia, não apresentar restrição alimentar, ter boa aparência física, manter hábitos de controle e prevenção de doenças e ser jovem:

"Eu vejo assim uma pessoa com saúde é uma pessoa que não está esmorecida, que está legal, está de bem com a vida, sempre sorri direto, porque a partir do momento que a pessoa deixa de sorrir ou de cumprimentar alguém, sei lá, e começa ficar introvertida daí já, eu creio, não sou médico, mas eu creio que já é o princípio de alguma doença, tem alguma coisa errada". (H1 -51 anos)

"Eu acho que tem saúde quando... dorme bem". (H11 - 56 anos)

“... se tem disposição, aí então tem saúde, não é”? (H10 - 30 anos)

"A pessoa que tem saúde é a pessoa que pode comer o que tem vontade... que pode comer uma carne aí gorda... Eu falo, a única coisa que a gente luta hoje é comer, Essa pessoa pra mim tem saúde". (H7 - 38 anos)

"Acho que quando éjovem. Agente mesmo, eu era jovem não sentia nada e pra mim, eu nunca ficava doente na vida. Aí, depois aparece uma dor na perna, no braço, problema aqui, problema acolá". (M2 - 59 anos)

Em relação às concepções, chamou-nos a atenção o fato de as mulheres, em sua maioria, relacionarem saúde à aparênciafísica e os homens à capacidade para o trabalho:

"Ah, sei lá. É difícil explicar ((risos))? Acho que é quando é vistoso". (M9 -35 anos)
"Eu acho que pessoa gorda, também gorda demais não tem saúde não". (M13-30 anos)

"Você vê quando uma pessoa está magra demais... ai ela não está bem não. Aí ela também não tem saúde não". (M15 - 43 anos)

"A pessoa tem saúde está bem, tem emprego, se ocupa. Senão não tem como. Se não tem o que fazer, não pensa coisa boa, no caso, aí só vai... Quando eu estou trabalhando eu não penso nisso (na doença)..." (H6 - 52 anos)

"Pela aparência e pelo que eu conheço dela. Se ela está bem, está trabalhando normal". (H5-31 anos)

Já no que se refere a ter hábitos relacionados com controle e prevenção os homens se destacaram, pois utilizaram com muita freqüência o termo prevenção como forma de se proteger contra enfermidades. Também foram eles que mais fizeram referência à necessidade de cuidados com os vícios, mais especificamente com os excessos com o fumo, as bebidas e as drogas.

É interessante observar que dos seis informantes que citaram o consumo de álcool, tabaco e outros tipos de droga, como prejudiciais à saúde, a maioria deles (quatro), faz uso do cigarro ou de bebidas alcoólicas (uma mulher e três homens)

"... eu estou com 59 anos. Até hoje eu não tive assim, nada até hoje que eles (médicos) dissessem você tem que cuidar por isso ou por aquilo. Então eu me considero um cara sadio, porque até hoje eu já fui em médico, não muitas vezes, mas, as vezes que eu já fui, sempre a pessoa (médico) disse:_Você estábem, você não tem nada, você está tranqüilo, então eu me sinto bem".(H2 - 59 anos)

\section{O olhar sobre a própria saúde}

Ao se investigar a ocorrência de distúrbio relacionado à saúde nos doze meses que antecederam a coleta de dados, constatou-se que mais da metade dos entrevistados $(51,7 \%)$ referiram não ter apresentado nenhum problema, sendo que os homens relataram menos a ocorrência de doenças do que as mulheres. Apenas $23 \%$ deles referiu algum infortúnio no período:

"Não, só coisa simples como resfriado" (H8-36 anos).

A maior parte dos homens fez questão de demonstrar que estava saudável e em condições de trabalhar:

"Não, que eu saiba eu não fiquei doente não" (H3 - 38 anos).

"Eu nem me lembro qual foi a última vez que eu fiquei doente. Só trabalho, só tenho tempo para trabalhar. Eu não tenho nada na saúde" (H10 - 30 anos).

A diferença na expressão da doença entre as pessoas ocorre pela maneira como cada uma categoriza seus sintomas e incapacidades e de acordo com o contexto sociocultural em que estão inseridas ${ }^{(15)}$.

A maioria das queixas foi feita pelas mulheres (85\%), sendo que a maioria delas $(75 \%)$ relatou ter apresentado uma ou mais doenças no período:

"Eu tomo remédio para pressão alta. Tenho problema de coluna... Aparece uma dor na perna, no braço, problema aqui, problema acolá" (M2 - 59 anos).

"Eu tenho pressão alta, é má circulação. Aí começa doendo as pernas, dói nas costas, na coluna, dói nas mãos, aquela dor ferroando. Depois dos 40 anos, eu sofri bastante com bronquite também" (M3-54 anos). 
Aidentificação de maior morbidade das mulheres em relação aos homens, é coerente com o que tem sido identificado em outros estudos, abordando as diferenças nas condições de saúde por ambos os sexos ${ }^{(6,7)}$. Além disso, a auto-avaliação das mulheres sobre o seu estado de saúde é, em geral, pior do que no sexo masculino ${ }^{(16)}$. As mulheres costumam estar mais atentas às sensações e percepções com relação ao seu corpo e a demonstrar mais cuidado para com ele do que os homens ${ }^{(10)}$.

No total foram referidos pelos entrevistados oito tipos diferentes de problemas de saúde, ocorridos no período dos últimos doze meses. A hipertensão arterial foi a doença mais citada, representando $46 \%$ de todas as queixas. No que diz respeito a esta patologia, as mulheres, e em especial as com idade entre $39 \mathrm{e}$ 59 anos, foram responsáveis por todas as reclamações:

"De um ano para cá? Olha desde que meu menino nasceu eu tenho problema de pressão alta. Desde a gravidez eu tenho problema de pressão alta... Eu vou sempre medir... controlar a pressão também. Vou no posto pegar remédio para pressão, as vezes eu vou duas, às vezes vou três vezes por semana. Tem que cuidar direto. Tomo remédio para pressão três vezes no dia" (M5 - 39 anos).

A hipertensão é uma doença altamente prevalente em nosso meio, acometendo no Brasil um percentual de $15 \%$ a $20 \%$ da população adulta ${ }^{(17)}$. É importante ressaltar que a maior ocorrência de hipertensão arterial em mulheres do que em homens foi constatada no estado do Paraná e no Brasil como um todo ${ }^{(17)}$, o que acredita-se que possa ocorrer, provavelmente, porque os homens com menos de 50 anos são menos diagnosticados que as mulheres, pois além de referirem menos seus sintomas também procuram pouco os serviços de saúde ${ }^{(18)}$. Contudo, é importante destacar que, no decorrer das entrevistas um dos homens (H11- 56 anos) relatou fazer uso de medicamentos antihipertensivos, porém, em momento algum de sua entrevista mencionou ser portador de doença hipertensiva, mesmo quando indagado sobre a presença de algum problema de saúde.

Por ordem de freqüência, observamos que os problemas de coluna e depressão constituem o segundo problema mais referido pelos entrevistados (42,8\%), sendo ambos também citados apenas por mulheres.

As mulheres que referiram dores lombares têm idades entre 35 e 59 anos e desenvolvem atividades diversas como "do lar", faxineira e professora. Elas comentam que embora estas dores sejam bastante incômodas, não deixam de realizar as atividades do dia a dia, e buscam por ajuda do médico sempre que apresentam os sintomas:

“... a dor nas costas não atrapalha, (o desempenho dos serviços domésticos) eu faço, mas dói sim, eu faço mais dói... Sempre, sempre eu tenho que estar no médico para tirar chapa para ver como é que está. Na última radiografia, ele (médico) viu que estava torta mais não passou remédio, eu tenho que ir esse ano, agora, de novo para ver". (M2 - 59 anos)

"Eu tenho muita dor na coluna, às vezes de noite eu quase não durmo. 0 doutor disse que é peso. Há uns tempos atrás ele passou um diclofenaco para mim, eu tomei, melhorou, mais só que ele mandou eu fazer um regiminho sabe, ai eu emagreci. Acabaram as dores nas costas e a dor no pé. Agora voltei a engordar de novo, voltou a dor na coluna". (M9-35 anos)

A dor na colunaé um problema que faz parte do contexto de dores lombares e as mulheres apresentam um grande risco para sua manifestação. Pois cada vez mais, associam as tarefas domésticas ao trabalho fora de casa, o que exige mais esforço de seu corpo, além das características anatômicas femininas (menor estatura, menor massa muscular e óssea, articulações mais frágeis, entre outras), que podem colaborar para o surgimento destas dores ${ }^{(19)}$.

Depressão foi a terminologia utilizada pelas entrevistadas para designar a falta de disposição para o desempenho das atividades diárias e foi citada por 19\% das mulheres, todas com idade inferior a 39 anos. Suas justificativas estavam relacionadas à falta de ocupação e às poucas atividades de lazer existentes no município:

“... eu tenho problema de... depressão, então eu tenho que tomar remédio para depressão... Ah, eu tento não ficar doente (deprimida), apesar de que eu sou muito nervosa... tento me distrair, apesar de que aqui não tem muito para fazer. Eu era agitada..." (M5-39 anos)

"No momento acho que eu estou com depressão. O médico falou. Eu não consigo dormir, não tenho paciência com nada, mas não é por isso que não vou viver bem. Eu acho que estou doente... acho que estou sem trabalho... eu acho que é por isso mesmo. Você viu o tamanho da cidade"? (M11 20anos)

Os problemas circulatórios foram citados pelo mesmo número de homens e mulheres representando $6,9 \%$ do total de queixas.

“... é má circulação. Você, veja meus dedos assim... Estão tudo dormente, nos pés. Má circulação. Depois que terminou (menstruação), que entrou essa menopausa, aí deu esse problema de má circulação. Faz um ano. Eu via que estava aquela dorzinha nos dedos e meio dormente... estava com má circulação. Eu fico muito parada, sem caminhar. Ele (médico) mandou eu caminhar. Só que eu comecei caminhar e parei ((risos)). Eu parei, mais tem que caminhar" (M3-54 anos).

"O problema que eu tive, é falta de circulação, sabe... Tinha assim, formigação na perna, nos dedos... Aí ele (médico) receitou remédio. Eu já tive antes isso, eu falei para ele como era, e aí eu tinha até a receita guardada, aí mostrei para ele, aí ele falou para tomar. Não deu mais" (H3 -38 anos).

A doença venosa crônica dos membros inferiores atinge cerca de 40\% da população em geral, sem apresentar grandes diferenças na prevalência entre homens e mulheres ${ }^{(20)}$. Outras doenças também foram citadas, como os problemas dentários, amenorréia, infecção urinária, otite e pneumonia. Cada uma delas foi referida por uma pessoa entrevistada, sendo todas mulheres com exceção dos problemas dentários, que foi citado por um homem $(3,4 \%)$

\section{O intinerário terapêutico}

Diante da doença, os informantes revelaram que, as primeiras condutas adotadas para tentar resolver um problema de saúde são: 1) automedicação $(41,4 \%)$, em alguns casos associada à utilização de remédios caseiros em forma de chás e xaropes; 2) procura pelos serviços oficiais de saúde (34, $5 \%)$; 3 ) procura pela farmácia $(24,1 \%)$. O que se constatou foi que a maior parte dos entrevistados costuma cuidar de sua saúde a princípio por conta própria, recorrendo ao sistema informal de saúde.

Este tipo de cuidado é desenvolvido naturalmente pelas pessoas ao longo de suas vidas. É o cuidado que se tem desde a infância, transmitido pelos pais, parentes, vizinhos, amigos, meios de comunicação, professores, entre outros. Ele constitui o Sistema Popular de Saúde ${ }^{(9)}$. Esta medicina popular refere-se a "[...] todas as representações e práticas relativas à saúde e à doença que se manifestam independentemente do controle da medicina oficia|"(21). Por outro lado existe o sistema oficial de assistência à saúde, no qual se apresenta a "[...] medicina institucionalizada e regulamentada pelo poder constituído" (21). Este sistema está relacionado à medicina científica, a qual segue regras e papéis específicos em ambientes especializados como hospitais, consultórios médicos entre outros e inclui entre seus profissionais médicos e enfermeiros ${ }^{(9)}$.

Na maior parte das respostas, a auto-medicação foi citada, em associação à medicamentos caseiros para a solução de manifestações mais simples, como gripe ou resfriado. Autilização de medicamentos caseiros, principalmente de chás, associados ou não com remédios industrializados nos casos de 
resfriados, foi citada por $27,5 \%$ dos informantes. Esta prática foi mais comum entre as mulheres (37,5\%) do que entre os homens $(15,4 \%)$ :

"Geralmente quando é uma gripe a gente faz xarope. Faz chá de limão ou pinga limão no caféde manhã... Minha avó e minha mãe são descendentes de índio, e não tomam remédio do posto" (M14-25 anos).

"Tomo chá de guaco, geralmente com comprimidoAgente foi criado assim desde pequeno" (H9-36 anos).

Constatou-se que problemas como febre, dores de cabeça, gripe e cólica entre outros são situações que, na opinião da maior parte dos participantes, não necessitam de acompanhamento médico. Em geral, a busca pelo serviço de saúde ocorre apenas diante da suspeita de maior gravidade da doença:

"Eu não vou em médico por causa de porcaria não"(H7-38 anos).

"Sótrabalho, sótenho tempo para trabalhar Eu não tenho nada na saúde"( $H$ $10-30$ anos).

"Se é uma dor de cabeça, assim, eu tomo um remédio em casa mesmo, se for alguma coisa mais grave eu vou no médico" (M13-30 anos).

"Depende do tipo (de doença), se for pressão eu já medico, vou ao médico, ou vou na farmácia. Agora se for uma gripe, uma coisa assim, eu tenho medicamento em casa eu mesmo tomo"(M16-40 anos).

A farmácia é, para $24,1 \%$ dos indivíduos, considerada como primeira opção na busca pela solução de seu problema de saúde. Esta prática é três vezes maior entre os homens (38,5\%) do que entre as mulheres $(12,5 \%)$. A justificativa para esta atitude, conforme pôde ser observado nos relatos envolve: a facilidade no atendimento, justificada pela amizade com o proprietário, que mantém o comércio há vários anos no município e pela confiança neste profissional; pela agilidade no atendimento que dispensa agendamentos, como ocorre na Unidade Básica de Saúde; e também, pela falta de credibilidade nos profissionais que prestam atendimento no serviço de saúde municipal.

"Quando eu estou com cólica, dor de cabeça eu vou na farmácia, tomo Doril, atroveran, vou direto na farmácia. Ir no posto não resolve". (M11-20 anos).

"Ah! Eu procuro, a primeira coisa que eu procuro quando estou doente, tem um farmacêutico aí que ele é muito meu amigo... Primeiro eu passo por ele. Depois, se ele acha que ele não tem condições... se não tiver, já fala: Olha você tem que ir para o médico" (H2 - 59 anos).

"É, o costume do povo daqui é esse mesmo (procura primeiro pela farmácia). É que o farmacêutico é melhor do que o médico. Já está aqui tem uns 30 anos. O pessoal mesmo prefere mais ele do que o médico" (H5 -31 anos).

"Como aqui em Porto Rico a gente tem muita confiança no seu (...), dono da farmácia, e conversa com ele e depois se não der certo eu vou no médico" (H8-36 anos).

Estudo realizado em um bairro do município de Balneário Camboriú -SC, abordando o Itinerário Terapêutico adotado por seus moradores constatou que a busca pela solução de problemas de saúde esbarrava em questões relativas à oferta de serviços. Observou-se que a maior dificuldades dos entrevistados referia-se ao horário de atendimento do Posto de Saúde disponível à população e a dificuldade no agendamento de consultas. Para suprir as dificuldades encontradas na utilização do serviço oficial de saúde, os moradores do bairro buscavam pela farmácia ou adotavam a auto medicação como alternativas de cuidado ${ }^{(22)}$

Constatou-se no presente estudo que as mulheres pesquisadas tem uma maior iniciativa do que os homens em procurar pelo serviço médico como primeira alternativa quando a doença se manifesta (34\% e $23 \%$ respectivamente).

"Vou, vou no médico, não deixo de ir, porque Ele (DEUS) deixou a medicina... e se a gente não for no médico... os homens também são de Deus, porque ele deu o caminho para ajudar a gente com medicamento, com cirurgia." (M3-54 anos)

"Olha eu só tomo remédio assim que eu pego no posto, porque a gente não tem opção... Vou no posto pegar remédio para pressão, as vezes eu vou duas, às vezes vou três vezes por semana. Tem que cuidar direto" (M539 anos).

Estudo realizado no Rio de Janeiro constatou uma maior utilização dos serviços oficiais de saúde por parte das mulheres ${ }^{(11)}$. Os autores destacam diferenças de gênero relacionadas ao motivo pelo qual este fato ocorre e, segundo eles, as mulheres buscam mais os serviços para exames de rotina e prevenção e os homens procuram mais por motivo de doença.

As questões da busca de serviço de saúde neste estudo possibilitou a inferência de alguns fatores que podem influenciar os homens a não procurarem por consultas médicas no âmbito ambulatorial, quais sejam: 1) o fato do homem acreditar ter seu tempo perdido na espera pela consulta nas Unidades Básicas de Saúde, sendo a utilização de outros serviços como farmácias ou ProntoSocorros uma forma de agilizar o atendimento; 2) a idéia de que, nas UBSs, os serviços são destinados, em sua maioria, às mulheres, crianças e idosos; 3) a idéia de que os serviços de saúde são um "espaço feminilizado" (maioria dos trabalhadores destes serviços são mulheres). Esses conceitos masculinos, de acordo com 0 autor, podem justificar a procura por outras formas de atendimento além da consulta médica(5).

Algumas situações compatíveis com as citadas anteriormente, segundo os relatos, dificultam o atendimento e a resolução dos problemas de saúde no município, gerando a insatisfação com serviços oferecidos pela UBS. Estas observações foram feitas tanto pelos homens quanto pelas mulheres. Isto se deve ao fato de seu itinerário consistir no percurso clássico das pessoas das classes sociais mais desfavorecidas, que procuram tratar-se em serviços públicos antes de serem encaminhados à serviços especializados, em geral, também públicos.

As reclamações apresentadas pelos informantes sobre estes serviços foram freqüentes e decorrentes de vários fatores. Dentre eles estão: 1) o horário disponibilizado pelo serviço para o atendimento médico; 2) a falta do número de consulta suficientes para atender à demanda; 3) a dificuldade no agendamento de consultas e/ou exames; 4) a falta de especialidades médicas e a dificuldade em conseguir encaminhamento à outras instituições especializadas eà exames complementares; 5) a dificuldade na aquisição de medicamentos; 6 ) a falta de credibilidade no serviço médico oferecido: 7) a dificuldade de relacionamento entre os pacientes e os profissionais:

"Achapa em Paranavaí, Loanda se for pago. Aí os médicos, eles marcam para a gente ir para Paranavaí. Eles levam (Prefeitura). Aí vai todo mundo, sempre vai cheio, minha filha... direto. É que as vezes a gente não tem o dinheiro para pagar. Então a gente tem que esperar pela prefeitura... Tem vezes que demora, se tiver muita gente demora, dois meses, três, tem hora que até não gosto de ir no posto, porque chega lá, marca, passa dois, três meses, a pessoa..., tem que esperar" (M2 - 59 anos)

“... principalmente aqui, é bem escasso, se precisar alguma coisa no posto, de exame, tirar $R X$, você tem que ir lá para Paranavaí... E quando tem vaga, até eles marcarem... é complicado" (M7-33 anos). 
"Eu não vou na farmácia porque eu não tenho dinheiro para comprar remédio, se não eu ia. No posto às vezes tem o remédio, às vezes não tem"(M10-28 anos).

"Quando eu tenho alguma coisa eu não vou no médico daqui. O médico daqui não adianta... Ir no posto não resolve... Eu tenho "raiva" do pessoal do posto. Às vezes a pessoa está doente, chega lá, não tem vaga" (M11 -20 anos).

"Não gosto de ir no médico porque as vezes eu vou, já não resolve, aí eu não vou mais... Faz tempo que eu fui com problema nas costas, uma mancha que coça. Deu remédio, eu passei, não adiantou nada... Às vezes eles (funcionários da UBS) reclamam:_As mesmas pessoas sempre no posto! Mais às vezes toma remédio, não resolve, volta no posto. $O$ médico às vezes não dá conta de atender todo mundo quando as pessoa gostam dele... Para fazer no posto (exames) precisa esperar mais de um ano." (M12-54 anos).

"... eu procurei um otorrino em Loanda. Aqui não tem especialista, e também, eu trabalho de manhã e a tarde o médico só atende três vezes por semana, aí quando atacou mesmo, eu fui atrás de consulta e não tinha mais, ai eu preferi ir na farmácia... melhorou um pouco mais continuou, ai eu fui consultar em Loanda. O especialista é de Paranavaí. Ai resolveu... (M6-38 anos).

Em geral, nas populações menos favorecidas, a dificuldade de conseguir atendimento resulta em baixa expectativa para os indivíduos. 0 simples fato de ser atendido já pode produzir satisfação, pois as pessoas não esperam muito das instituições públicas ${ }^{(23)}$. Melhor poder aquisitivo e grau de instrução, além do bom relacionamento com os profissionais de saúde, de acordo com os relatos, podem ser um facilitador no acesso ao atendimento e à satisfação do indivíduo:

"Também, eu tenho plano de saúde, mas utilizo o daqui também para coisinha simples. Mas quando é problema mais complicado eu tenho plano de saúde que eu uso, não é? Inclusive às vezes, quando eu sinto algum probleminha assim, se eu vejo o médico, eu falo: Estou com o problema tal. Ele (o médico) fala: Toma isso. Ele pega e passa num jornal mesmo (a receita), entende? Então é fantástico. Para mim, não existe problema até agora não" (H1-51 anos).

"Eu freqüento este Posto, mais muito pouco, eu prefiro pagar. Aqui é muito demorado. Um especialista, leva meses, e lá você vai e paga, tem médico toda hora, pede os exame..." (M6 - 38 anos).

\section{“... O médico falou. Não procurei (o médico). Foi de conversar na rua, ele é amigo da minha tia" (M11 - 20 anos).}

"Dentista não tem... Me preocupo, porque se ficar doente aqui é complicado. Se partiu para ficar doente édifícil, porque éa hora que ocupa dinheiro. Agente vê ali, as pessoas que ficam doentes, procuram, eles não atendem. Você fala:_Meu Deus! Porque aqui tem dois, três médicos... Como quando eu tive uma febre na ilha, fizemos exames (ele e várias outros ilhéus) e nunca soubemos o resultado... Médico é assim, às vezes tem dez pessoas, as dez tomam o mesmo remédio, todo mundo..." (H6 52 anos).

"Por exemplo o Dr.(...) chega lá:_O que você tem? Só aquele remedinho e pronto... Eu estou com um exame de vista marcado desde o ano passado. As coisas são muito enroladas, por isso que a gente não vai atrás... Dentista não tem. É muita fila, é um "complô" esse posto de saúde. Para remédio por exemplo: tem, mas não é qualquer pessoa que consegue pegar" (H6-52 anos).

A diferença na forma de atendimento e/ou relacionamento entre os indivíduos das diferentes classes sociais e o médico foi descrita por Boltanski (24), no sentido de que quando o indivíduo apresenta um maior poder aquisitivo e maior grau de instrução, ele tem facilitada a sua aproximação com o médico, além de haver um maior entendimento sobre o processo de doença e as condutas a serem tomadas para atingir o restabelecimento de sua saúde.

Por outro lado, os indivíduos de classes populares, apresentam maior dificuldade de acesso ao serviço, e quando esse acesso se concretiza, existe uma barreira na comunicação e entendimento entre o profissional e o paciente. Este, segundo 0 autor, enfrenta uma condição de inferioridade frente aos profissionais com maior grau de instrução, julgando-se incapaz de discutir sobre seu problema e muitas vezes aceitando as imposições do tratamento, por não ter possibilidade de acesso à outro serviço. Esta questão aparece de forma muito clara em um dos depoimento que chamou-nos a atenção pela indignação do entrevistado:

"A gente vê ali as pessoas que ficam doentes, procurarem, eles não atendem, você fala:_Meu Deus... Se tiver alguém de lá de dentro é que consegue (remédios). Então é complicado. Agente vê ali gente que não precisa, pegando remédio, e gente que precisa não consegue... É muito complicado..." (H6-52 anos).

A insatisfação da população com os serviços de saúde oferecidos e a insuficiência dos mesmos tem gerado conflitos e distanciamento entre profissionais, mas isto pode ser melhorado por meio de projetos que visem uma maior participação popular, e uma educação para os profissionais com vistas a quebrar preconceitos em relação à população(25).

A satisfação do indivíduo que utiliza o serviço de saúde diz respeito à percepção subjetiva que este tem do cuidado que recebe. O grau de satisfação ou de insatisfação pode estar relacionado às suas relações interpessoais com o profissional do serviço. Outros aspectos como a infra-estrutura dos serviços (existência de equipamentos, medicamentos, etc.), ou as questões de ventilação, conforto, entre outros interferem no grau de adesão do paciente ao tratamento e às ações preventivas recomendadas pelos profissionais ${ }^{(26)}$. Os serviços de saúde contribuem para a formação da concepção de saúde e doença, permitindo às pessoas avaliarem e escolherem em aderir ou não às formas de tratamento oferecido por seus profissionais ${ }^{(27)}$.

Das 16 mulheres entrevistadas, nove fazem uso do serviço de saúde municipal. Segundo seus relatos, quando sentem que estão apresentando algum problema, elas procuram pela UBS. Embora estas mulheres utilizem este serviço, mais da metade delas apresentam reclamações a respeito de algum aspecto na oferta dos serviços.

Com relação às mulheres que referiram não freqüentar o serviço de saúde do município (31\%), todas apresentavam ensino médio ou superior. Vale destacar que, estas mulheres deixaram bastante claro o fato de que não deixam de procurar o médico quando se sentem doentes, mas sim, que 0 fazem em outros municípios, optando pelos serviços médicos particulares. A única exceção foi uma das entrevistadas (Nível Fundamental Incompleto) que referiu não utilizar o serviço de saúde por seguir as concepções de saúde da mãe e da avó, que por serem descendentes de índios, utilizam-se apenas de ervas para o tratamento das enfermidades.

O perfil de utilização do serviço de saúde, descrito pelos participantes da pesquisa, do sexo masculino foi diferente. Apesar de $46 \%$ deles terem dito que freqüentam a UBS, a maior parte, o faz apenas quando sente que a situação de saúde é grave.

Apenas um entrevistado utiliza o serviço de saúde com freqüência. Sua justificativa se dá, pelo fato de ter sido submetido à uma cirurgia bariátrica, tendo a necessidade de controle freqüente do seu estado de saúde por meio de avaliação clínica e da realização de exames periódicos. Entretanto vale destacar sua opinião sobre esse fato: 
"Eu me recusava a verificar pressão antes da cirurgia. Porque minha pressão era muito alta, elas (Agentes de Saúde) falavam:_ Você tem que ir no médico ver a sua pressão... Aí elas falavam:_Está 18 por 12... e eu dizia:_Ah deixa, estábom. Agora eu vejo, está 12 por 8, por 9, agora está bom. Acho que a gente só lembra de correr lá, a hora que a "coisa" pega. Mais você vê, hoje eu faço porque o médico exige. Acada seis meses faço uma bateria de exames completos. Se ele (médico) não exigisse, eu não fazia de jeito nenhum. Eu penso, para que eu vou fazer exame se eu não estou doente? Não estou sentindo nada? De repente a doença já está ali, fácil de curar, ou qualquer coisa... Precisou acontecer comigo (doença) para mim acordar" (H13-42 anos).

Dos homens que referiram não fazer uso do serviço oferecido pela UBS (54\%) estão: os que utilizam o serviço médico particular em outros municípios (um); os que têm convicção de que não necessitam de cuidados (três) e os que somente buscam por ajuda do profissional da farmácia do município (quatro). As atitudes frente à utilização do sistema oficial de saúde na visão de alguns participantes já havia sido descrita em estudo anterior que inferiu que o sistema oficial de assistência à saúde do município, possivelmente não atende a todas as necessidades da população(28).

\section{CONSIDERAÇÕES FINAIS}

Do conjunto de dados obtidos com a exploração dos temas propostos considera-se que existe uma diferença na visão sobre a própria saúde entre homens e mulheres no município de Porto Rico que, embora seja de pequeno porte, não difere de dados encontrados em estudos anteriores realizados no Brasil.

Constatou-se que as mulheres adultas do município de Porto Rico reconhecem mais os estados mórbidos do que os homens na mesma faixa etária. Elas apresentam uma maior preocupação com seu estado de saúde e dão maior importância às transformações que ocorrem em seu corpo, identificando mais as doenças.

Para a maioria dos homens entrevistados as doenças são esporádicas, e normalmente não necessitam de atenção ou preocupação, que possam leválos a perder tempo ou que os desvie de suas atividades diárias. Eles destacam que somente reconhecem mudanças em seu organismo como patológicas se as considerarem graves.

O Itinerário Terapêutico adotado pelos entrevistados segue uma ordem que, em sua maioria utiliza a automedicação, seguido da busca pelo profissional do estabelecimento comercial (farmácia) do município e por fim, a busca pelo serviço oficial de saúde.

As mulheres foram as que mais relataram fazer uso da UBS do município, enquanto que a maioria dos homens referiram procurar pela orientação do dono da farmácia, justificando sua atitude pela maior facilidade em receber 0 atendimento.

A maior parte dos indivíduos entrevistados encontrava-se em uma camada menos favorecida da população, apresentando baixa renda familiar sendo que quase metade deles apresentava nível educacional inferior ao Fundamental incompleto. Este fato pode levar a uma sensação de inferioridade com relação aos profissionais de saúde o que dificulta o acesso ao serviço e a relação de troca de informações entre profissional e cliente. Diante deste fato constatou-se uma insatisfação dos entrevistados no que se refere ao serviço oferecido pelo sistema oficial de saúde do município. Segundo eles, algumas questões como a dificuldade no agendamento de consultas e exames especializados, além da relação entre profissionais e clientes dificulta o acesso das pessoas de baixa renda que dependem exclusivamente deste serviço para a solução de seus problemas de saúde.

O desafio a ser lançado deve ser para a UBS, com o objetivo de estudar o desenvolvimento de trabalhos voltados à atenção aos indivíduos que necessitam do senviço público de saúde, com visibilidade nas necessidades tanto de homens como de mulheres no contexto sócio cultural em que estão inseridos, com 0 desenvolvimento de ações que favoreçam o conhecimento de suas necessidades em saúde 0 acesso aos serviços para ambos os sexos.

\section{REFERÊNCIAS}

1. Alves PC. A experiência da enfermidade: considerações teóricas. Cad Saúde Pública 1993; 9(3): 263-71.

2. Krieger N. Gender, sexes and health: what are the conections and why does it matter? Int. J. Epidemiol 2003; 32(4): 652-7.

3. Louro GL. Gênero, história e educação. Educ Realid 1995; 20(2): 101-32.

4. Schraiber LB, Gomes R, Couto MT. Homens e saúde na pauta da saúde coletiva. Ciênc Saúde Coletiva 2005; 10(1): 7-17.

5. Figueiredo W. Assistência à saúde dos homens: um desafio para os serviços de atenção primária. Ciênc Saúde Coletiva 2005; 10 (1):1059.

6. Laurenti R, Jorge MPM, Gotlieb SLD. Perfil epidemiológico da morbi-mortalidade masculina. Cienc Saúde Coletiva 2005; 10(1): 35-46.

7. Lebrão ML, Carandina L, Magaldi C. Análise das condições de saúde e de vida da população urbana de Botucatu, São Paulo (Brasil). IV - Morbidade referida em entrevistas domiciliárias, 19831984. Rev Saúde Pública 1991; 25(6): 452-60.

8. Pinheiro RS, Travassos C. Estudo da desigualdade na utilização de serviços de saúde por idosos em três regiões da cidade do Rio de Janeiro. Cad Saúde Pública 1999; 15(3): 487-96.

9. Helman CG. Cultura, saúde e doença. Porto Alegre (RS): Artes Médicas; 2006

10. Loyola MA. Médicos e curandeiros: conflito social e saúde. São Paulo (SP): Difel; 1984.

11. Pinheiro RS, Viacava F, Travassos C, Brito AS. Gênero, morbidade, acesso e utilização de serviços de saúde no Brasil.
Ciênc Saúde Coletiva 2002; 7(4): 687-707.

12. Sponchiado D, Eidt NM, Tomanik EA. Representações socias sobre 0 trabalho elaboradas pela população economicamente ativa de uma comunidade ribeirinha do rio Paraná. Acta Scientiarum 2002; 24(1): 181-8.

13. Minayo MCS. Saúde-doença: uma concepção popular da etiologia. Cad Saúde Pública 1988; 4(4): 363-81.

14. Caprara A. Uma abordagem hermenêutica da relação saúdedoença. Cad Saúde Pública 2003; 19(4): 923-31.

15. Mendonça RT. Representações de mulheres idosas usuárias de um serviço de saúde: relações entre consumo de calmantes, gênero e envelhecimento [dissertação]. Ribeirão Preto (SP): Faculdade de Medicina da Universidade de São Paulo; 2005.

16. IBGE. Pesquisa nacional por amostra de domicílios. Rio de Janeiro 1998. [citado em: 2006 dez 5]. Disponível em: URL: http:/l www.ibge.gov.br/home/estatistica/populacao/trabalhoeren dimento/pnad98/saude/defaulttabbrasil.shtm?c=1

17. Ministério da Saúde (BR). Morbidade hospitalar do SUS: CID-10, 2006. [citado em: 2006 nov 23]. Disponível em: URL: http:// www.datasus.gov.br/cgi/tabcgi.exe?sih/mpr.def

18. Verbrugge LM. Sex differentials in health. Public Health Rep 1982; 97(5): 417-37.

19. Silva MC, Fassa AG, Valle NCJ. Dor lombar crônica em uma população adulta do sul do Brasil: prevalência e fatores associados. Cad Saúde Pública 2004; 20(2):377-85.

20. Maffei FHA. Varizes dos membros inferiores: epidemiologia, etiopatogenia e fisiopatologia. In: Maffei FHA, Lastoria S, Yoshida WB, Rollo HA, organizadores. Rio de Janeiro (RJ): Medsi; 1995. 
Merino MFGL, Marcon SS.

p. 939-49.

21. Queiroz MS. Estratégias de consumo em saúde entre famílias trabalhadoras. Cad Saúde Pública 1993; 9(3): 272-82.

22. Schoze AS, Silva YF. Riscos potenciais à saúde em itinerário de cura e cuidado. Rev Cogitare Enferm 2005; 10(2): 9-16.

23. Vaitsman J, Andrade GRB. Satisfação e responsabilidade: formas de medir a qualidade e a humanização da assistência à saúde. Ciênc Saúde Coletiva 2005; 10(3): 599-613.

24. Boltanski L. As classes sociais e o corpo. São Paulo (SP): Graal; 1989.

25. Craco PF, Almeida MCP. A participação popular nas comissões locais de saúde: mostrando vidas, contando lutas. Rev Bras Enferm 2004; 57(2): 188-92.

26. Silva LMV, Formigli VLA. Avaliação em saúde: limites e perspectivas. Cad Saúde Pública 1994; 10(1): 80-91.

27. Alves PC, Souza IM. Escolha e avaliação de tratamento para problemas de saúde: considerações sobre o itinerário terapêutico. In: Rabelo M. Experiência de doença e narrativa. Rio de Janeiro (RJ): Fiocruz; 1999. p. 125-38.

28. Bercini LO, Tomanik EA. Representações sociais sobre saúde e estratégias de enfrentamento das doenças entre as mulheres dos pescadores do município de Porto Rico, Paraná. Rev Cien Cuidado Saúde 2006; 5(supl): 71-6. 